\title{
Zinc and calcium apparent absorption from an infant cereal: a stable isotope study in healthy infants
}

\author{
BY LENA DAVIDSSON ${ }^{*}$, JILL MACKENZIE ${ }^{2}$, PETER KASTENMAYER ${ }^{1}$, \\ PETER J. AGGETT ${ }^{2 \dagger}$ AND RICHARD F. HURRELL'* \\ ${ }^{1}$ Nestec Ltd, Nestlé Research Center, PO Box 44, CH-1000 Lausanne, Switzerland \\ ${ }^{2}$ Department of Child Health, University of Aberdeen, Foresterhill, Aberdeen AB $2 Z D$
}

(Received 15 December 1994 - Revised 17 May 1995 - Accepted 26 May 1995)

\begin{abstract}
Fractional apparent absorption of $\mathrm{Zn}$ and $\mathrm{Ca}$ from a wheat-milk-based infant cereal was studied in six healthy infants (18-30 weeks old). Mineral absorption was measured by a stable-isotope technique based on faecal excretion of the isotopes. Each test meal $\left(40 \mathrm{~g}\right.$ cereal) was extrinsically labelled with ${ }^{70} \mathrm{Zn}$ and ${ }^{42} \mathrm{Ca}$ before intake. All faecal material passed during the $21 \mathrm{~d}$ following intake of the labelled test meal was collected on trace-element-free nappies. Individual stool samples were analysed for their content of ${ }^{70} \mathrm{Zn}$ and ${ }^{42} \mathrm{Ca}$ by thermal ionization mass spectrometry. Apparent absorption was calculated as intake minus total faecal excretion of the isotopes over 68-92 $\mathrm{h}$ after administration. The fractional apparent absorption values for $\mathrm{Zn}$ and $\mathrm{Ca}$ were 33.9 (SD 16.4) \% (range 19.2-63.9\%) and 53.5 (SD 12.6)\% (range $36 \cdot 7-71.7 \%$ ) respectively. Re-excretion of absorbed ${ }^{70} \mathrm{Zn} \mathrm{(>68-92} \mathrm{h} \mathrm{to} 21 \mathrm{~d}$ after intake of the labelled meal) was 0.44 (SD 0.38) \% of administered dose while only one infant re-excreted detectable amounts of ${ }^{42} \mathrm{Ca}(1.74 \%$ of administered dose). The analysis of individual stool samples confirmed that $72 \mathrm{~h}$ is a sufficient time period for complete collections of non-absorbed isotopes in faecal material from infants during the weaning period and that re-excretion of initially absorbed ${ }^{70} \mathrm{Zn}$ and ${ }^{42} \mathrm{Ca}(>68-92 \mathrm{~h}$ to $21 \mathrm{~d}$ after intake of the labelled meal) is negligible.
\end{abstract}

Zinc: Calcium: Weaning cereal: Stable isotope

The estimation of mineral and trace element requirements of infants, and the ability to establish dietary recommendations for these nutrients during early life, is limited by the lack of information from studies with infants. Nutrient bioavailability, which includes absorption and retention of the nutrients, is a necessary component in these estimates since only the absorbed and retained fraction of a nutrient can be utilized by the body. The bioavailability of trace elements and minerals varies over a wide range, depending on the amount of the mineral in the diet, the presence of enhancers and inhibitors as well as on the chemical form of the mineral in the diet (Turnlund, 1991). Information on the total content of minerals in the diet is thus only of limited value when evaluating the nutritional impact of different diets.

The stable-isotope technique is an excellent tool for studies of absorption and retention of trace elements and minerals, which does not introduce any risk to the subjects (Janghorbani et al. 1985; Turnlund, 1991; Davidsson, 1994). The 'faecal monitoring' method is the most commonly used for studies in infants. Previous studies of $\mathrm{Zn}$ and $\mathrm{Ca}$ absorption from infant foods by infants, using the stable-isotope technique, have measured absorption by analysing the non-absorbed isotope in faeces (Serfass et al. 1989; Ziegler et al. 1989). In some studies two isotopes of different elements were added simultaneously to

* Present address: Laboratory for Human Nutrition, Swiss Federal Institute of Technology, PO Box 474, CH8803 Rüschlikon, Switzerland.

$\uparrow$ Present address: Nutrition, Diet and Health Department, Institute of Food Research, Norwich NR4 7UA. 
the same test meal: Zn and Ca (Ehrenkranz et al. 1984, 1985), Zn and Cu (Ehrenkranz et al. 1989; Johnson \& Canfield, 1989) and Mg and Ca (Liu et al. 1989). All these studies used infant formula and/or human milk as the labelled test meal administered to young or premature infants, followed by analysis of the excretion of non-absorbed isotopes in faeces collected for $72 \mathrm{~h}$. For $\mathrm{Ca}$ a double-isotope technique also exists which is based on the simultaneous administration of two isotopes, one given orally and the other administered intravenously (Moore et al. 1985; Hillman et al. 1988; Yergey et al. 1990; Abrams et al. 1991, 1992, 1994). However, the need for venepuncture has limited the use of this technique for studies in healthy, non-hospitalized infants.

Little information is available on the absorption of minerals from weaning foods such as infant cereals and other semi-solid or solid foods consumed by older infants. In the present study we report on the use of the stable-isotope technique to measure the apparent absorption of $\mathrm{Zn}$ and $\mathrm{Ca}$ from a weaning cereal consumed by infants aged 18-30 weeks. Servings of the weaning cereal were extrinsically labelled with ${ }^{70} \mathrm{Zn}$ and ${ }^{42} \mathrm{Ca}$ and the faecal excretion of the stable isotopes was quantitated by thermal ionization mass spectrometry (TIMS). Faecal material was collected over $21 \mathrm{~d}$ in order to determine the time necessary to recover all the unabsorbed isotopes as well as to quantitate the rate at which the absorbed ${ }^{70} \mathrm{Zn}$ and ${ }^{42} \mathrm{Ca}$ were subsequently re-excreted in faeces after ingestion of extrinsically labelled weaning cereal.

\section{MATERIALS AND METHODS}

\section{Infants}

Six healthy term infants (two girls, four boys) were recruited at 'well-baby' clinics in Aberdeen at 18-30 weeks of age. All infants were fed with commercial cows' milk formulas. At least one serving per day of the infant cereal was fed as part of the infants' normal diet for approximately 1 week before the administration of the labelled test meal to ensure acceptance of the product.

\section{Stable isotopes}

$\mathrm{CaCO}_{3}$ enriched with ${ }^{42} \mathrm{Ca}$ and $\mathrm{ZnO}$ enriched with ${ }^{70} \mathrm{Zn}$ were purchased from Medgenix (Ratingen, Germany) and Oak Ridge National Laboratory (Oak Ridge, TN, USA) respectively. The ${ }^{42} \mathrm{CaCO}_{3}$ was dissolved in $10 \cdot 2 \mathrm{M}-\mathrm{HCl}$ to obtain ${ }^{42} \mathrm{CaCl}_{2}$ while ${ }^{70} \mathrm{ZnO}$ was transformed into ${ }^{70} \mathrm{ZnCl}_{2}$ by dissolution in $0.5 \mathrm{M}-\mathrm{HCl}$. The final concentration of $\mathrm{HCl}$ was $0.05 \mathrm{M}(\mathrm{pH} \mathrm{1.3})$ in the ${ }^{70} \mathrm{ZnCl}_{2}$ solution. Two batches of the enriched labels were prepared with slightly different concentrations. Total $\mathrm{Zn}$ was measured by atomic absorption spectrometry (AAS; model 975, Varian Techtron, Mulgrave, Australia). Allowance was made for the different atomic weights in the ${ }^{70} \mathrm{ZnCl}_{2}$ solution compared with the $\mathrm{Zn}$ standards. Total $\mathrm{Ca}$ was determined by isotope dilution using TIMS (Thermoquad, Finnigan MAT Model THQ, Bremen, Germany). Total concentrations of $\mathrm{Zn}$ and $\mathrm{Ca}$ were 508 and $551 \mu \mathrm{g} \mathrm{Zn} / \mathrm{ml}$ and 6.16 and $5.51 \mathrm{mg} \mathrm{Ca} / \mathrm{ml}$ respectively in the separate solutions. The isotopic composition of the stable-isotope solutions was checked by TIMS (Finnigan MAT). The solutions were filled into acid-washed, Teflon bottles and kept refrigerated until used. The ${ }^{42} \mathrm{Ca}$ labels contained $79 \cdot 35 \%{ }^{42} \mathrm{Ca}, 19 \cdot 60 \%{ }^{40} \mathrm{Ca}, 0 \cdot 164 \%{ }^{43} \mathrm{Ca}, 0 \cdot 862 \%{ }^{44} \mathrm{Ca}$ and $0.0343 \%{ }^{48} \mathrm{Ca}$. The stable-isotope solution of ${ }^{70} \mathrm{Zn}$ contained $88.35 \%{ }^{70} \mathrm{Zn}, 4.68 \%$ ${ }^{64} \mathrm{Zn}, 2.84 \%{ }^{66} \mathrm{Zn}, 0.494 \%{ }^{67} \mathrm{Zn}$ and $3.64 \%{ }^{68} \mathrm{Zn}$. Abundances are given as atom $\%$.

\section{Test meal}

A weaning cereal based on wheat with low (70\%) extraction rate $(400 \mathrm{~g} / \mathrm{kg}$ total solids) and skimmed milk powder ( $290 \mathrm{~g} / \mathrm{kg}$ total solids), (Cerelac, Nestlé SA, Vevey, Switzerland) was used in the present study. The cereal was fortified with $\mathrm{CaCO}_{3}$. One $40 \mathrm{~g}$ serving of the 
cereal was made up by the addition of $160 \mathrm{~g}$ deionized distilled water (16 M $\Omega$, Millipore (UK) Ltd., Watford, Herts.). The cereal was labelled with $370 \mu \mathrm{g}{ }^{70} \mathrm{Zn}$ and either $4.9 \mathrm{mg}$ ${ }^{42} \mathrm{Ca}$ (infants 1,3 and 4 ) or $4.4 \mathrm{mg}{ }^{42} \mathrm{Ca}$ (infants 2, 5 and 6) immediately before administration. The $\mathrm{Zn}$ and $\mathrm{Ca}$ contents in the weaning cereal were $12.7 \mu \mathrm{g} \mathrm{Zn} / \mathrm{g}$ and $5.13 \mathrm{mg} \mathrm{Ca} / \mathrm{g}$ resulting in $508 \mu \mathrm{g}$ native $\mathrm{Zn}(927 \mu \mathrm{g}$ total $\mathrm{Zn})$ and $205 \mathrm{mg}$ native plus fortification $\mathrm{Ca}(211 \mathrm{mg}$ total $\mathrm{Ca})$ in the labelled test meal. Each test meal also included $50 \mathrm{mg}$ carmine red as a faecal marker, except for the test meal given to infant no. 3 . The infants were given the labelled test meal at midday, about $4 \mathrm{~h}$ after the last intake of infant formula, under close supervision by one of the investigators to make sure that each child consumed the complete serving. No food or fluid was allowed for a period of approximately $2 \mathrm{~h}$ after intake of the test meal.

\section{Collection of faecal material}

A baseline faecal sample was collected before administration of the stable isotopes. The collection of all faecal material passed during $21 \mathrm{~d}$ after administration of the isotopes started immediately after intake of the test meal. Faeces were collected on disposable nappies (Lewis Wolf, Selly Oak, Birmingham, W. Midlands) and nappy liners (Boots, Nottingham, Notts.), previously deionized by soaking in 1 M-EDTA solution ( $\mathrm{Na}_{2}$ EDTA, $\mathrm{BDH}$ Ltd, Poole, Dorset) for $24 \mathrm{~h}$ followed by copious rinsing with deionized distilled water (16 M $\Omega$, Millipore (UK) Ltd). The nappies and liners were air-dried before being packed individually in zip-lock plastic bags until used. During the period of collection of faeces the infants' perineums were kept clean with deionized distilled water and no ointments were applied. Disposable plastic gloves were worn whilst the infants' nappies were changed. Soiled nappies and liners were placed in the zip-lock bags, labelled with name, time and date. Each home was visited daily by one of the investigators to supervise the parents and to collect faecal samples. The samples were kept frozen $\left(-20^{\circ}\right)$ until prepared for analysis.

\section{Sample preparation and analysis}

Solid pieces of faecal material were removed from the nappies and liners using an acidwashed plastic spatula. The remaining faeces were removed by soaking nappies and liners in $0.1 \mathrm{M}-\mathrm{HCl}$ for $24 \mathrm{~h}$ after which they were squeezed and rinsed with deionized distilled water to remove any staining. The washings were then added to the solid faecal material, homogenized using a titanium-bladed blender, frozen and freeze dried. All samples collected during the first $5 \mathrm{~d}$, as well as on day 21 , were processed separately. Remaining samples were pooled over several days: days 6-10,11-15 and 16-20. Pooled faecal samples were prepared by homogenization with $0 \cdot 1 \mathrm{M}-\mathrm{HCl}$, using the blender equipped with a titanium blade.

Freeze-dried samples of faecal material and of the weaning cereal powder were mineralized in quartz Erlenmeyer flasks in a muffle furnace at $520^{\circ}$ for $48 \mathrm{~h}$. The residual ash was dissolved in $4 \mathrm{ml}$ sub-boiled $\mathrm{HCl}$ and diluted to $25 \mathrm{ml}$ with ultra-pure water before analysis of total $\mathrm{Zn}$ and $\mathrm{Ca}$ by AAS. For $\mathrm{Ca}$ analysis. $\mathrm{La}_{2} \mathrm{O}_{3}$ was added to the samples equivalent to a final concentration of $10 \mathrm{~g} \mathrm{La} / \mathrm{kg}$. Accuracy of the analysis was tested by analysing standard reference materials (Bovine liver SRM 1577a, National Institute of Standards and Technology, Gaithersburg, MD, USA) and a pooled faecal sample as a laboratory standard. $\mathrm{CV}$ for $\mathrm{Zn}$ and $\mathrm{Ca}$ analysis of the pooled faecal sample were $2.6 \%$ $(n 25)$ and $4.6 \%(n 27)$ respectively. Dry weight was determined after drying at $105^{\circ}$ for $24 \mathrm{~h}$.

For mass spectrometric analysis, $\mathrm{Zn}$ was separated from matrix elements in faecal samples by ion exchange, using a slightly modified procedure to that described by Gotz \& Heumann (1987). Econo columns (Bio-Rad Laboratories, Glattbrugg, Switzerland) with 
an inner diameter of $7 \mathrm{~mm}$ were filled to a height of $70 \mathrm{~mm}$ with anion exchange resin (Type AG1-X8, 200-400 mesh, $\mathrm{Cl}^{-}$form, Bio-Rad). The resin was washed with $60 \mathrm{ml} 2 \mathrm{M}-\mathrm{HNO}_{3}$ using an Ismatec IPN 4 peristaltic pump (Ismatec SA, Zürich, Switzerland) at a flow rate of $1 \mathrm{ml} / \mathrm{min}$ and then regenerated to the chloride form with $100 \mathrm{ml} 1 \mathrm{M}-\mathrm{HCl}$. After addition

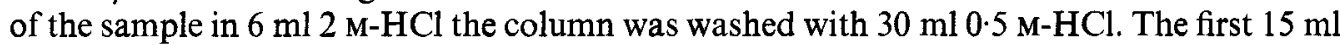
of solution eluted from the column after sample loading and rinsing was recovered for $\mathrm{Ca}$ separation. The $\mathrm{Zn}$ was eluted with $20 \mathrm{ml} 1 \mathrm{M}-\mathrm{HNO}_{3}$, evaporated to dryness and redissolved in $0.1 \mathrm{M}-\mathrm{HCl}$ to give a final concentration of $3 \mathrm{~g} \mathrm{Zn} / 1$. Ca was isolated from the sample by precipitation with ammonium oxalate (Merck, Darmstadt, Germany). A solution containing approximately $1000 \mu \mathrm{g}$ Ca was made alkaline with $250 \mathrm{~g} / 1 \mathrm{NH}_{3}$, heated to $70^{\circ}$ and $5 \mathrm{ml}$ of saturated ammonium oxalate solution $(\mathrm{pH} 10)$ was added. After cooling in an ice bath, samples were centrifuged and the precipitate was washed twice with $1 \mathrm{~g} / \mathrm{l}$ ammonium oxalate solution. The $\mathrm{Ca}$ oxalate was then converted to $\mathrm{CaCO}_{3}$ in a muffle furnace at $600^{\circ}$ overnight. $0 \cdot 3 \mathrm{M}-\mathrm{HNO}_{3}$ was added to obtain a final concentration of $5 \mathrm{~g} \mathrm{Ca} / 1$.

Stable-isotope ratios were measured with a computer-controlled quadrupole TIMS (Model THQ, Finnigan MAT) equipped with a Faraday cup, secondary electron multiplier, thirteen-sample turret and a reference pyrometer. Rhenium (Re) filaments of $0.04 \times 0.7 \mathrm{~mm}$ (99.98\% purity, Wagner Analysentechnik, Worpswede, Germany) were cleaned by out-gassing in a bake-out device (Finnigan MAT) under vacuum at 4.5 A for $20 \mathrm{~min}$ to remove impurities. For $\mathrm{Zn}$ analysis, samples were loaded onto $\mathrm{Re}$ single filaments together with a mixture of silica gel and $\mathrm{H}_{3} \mathrm{PO}_{4}$. The ${ }^{68} \mathrm{Zn}:{ }^{70} \mathrm{Zn}$ isotope ratio was determined at $1510^{\circ}$ using the secondary electron multiplier operated at an amplification of 25 relative to the Faraday detector. Ca samples were loaded according to the procedure described by Moore \& Machlan (1972) and measured by using $\operatorname{Re}$ double filaments at $1600^{\circ}$. Three blocks each with twelve scans across the isotope pattern were collected for each element in the peak-jumping mode. Data were analysed for outliers by a Dixon test (Dixon \& Massey, 1969). Measurements which had an internal standard deviation greater than the target precision of $0 \cdot 5 \%$ for ${ }^{40} \mathrm{Ca}:{ }^{42} \mathrm{Ca}$ and ${ }^{68} \mathrm{Zn}:{ }^{70} \mathrm{Zn}$ were discarded and analysis was repeated. Accuracy of the isotope ratio measurements was verified by analysis of $\mathrm{ZnNO}_{3}$ (Merck) and $\mathrm{CaNO}_{3}$ (Merck) as standards for natural isotopic composition. Relative accuracy of the ${ }^{68} \mathrm{Zn}:{ }^{70} \mathrm{Zn}$ isotope ratio measured was within $0.4 \%$ of the accepted value (International Union of Pure and Applied Chemistry (IUPAC), 1991). Relative external precision was $0.6 \%(n 13)$. The natural abundance ${ }^{40} \mathrm{Ca}:{ }^{42} \mathrm{Ca}$ was within $0.6 \%$ of the accepted value given by IUPAC (1991) with a relative external precision of $0.5 \%(n 9)$. The smallest enrichment that could be detected was consequently $1.8 \%$ for ${ }^{68} \mathrm{Zn}:{ }^{70} \mathrm{Zn}$ and $1.5 \%$ for ${ }^{40} \mathrm{Ca}:{ }^{42} \mathrm{Ca}$.

All acids used during analysis of $\mathrm{Zn}$ and $\mathrm{Ca}$ as well as for preparation of samples for mass spectrometric analysis were purified by sub-boiling in a quartz still (Kürner Analysentechnik, Rosenheim, Germany). Other chemicals were analytical grade purity. Only ultrapure water (18 M $\Omega$, Milli-Q water system, Millipore AG, Zürich, Switzerland) was used. To minimize contamination from vessel material only acid-washed quartz, Teflon and polyethylene containers were used.

\section{Calculations}

Fractional apparent absorption values for ${ }^{70} \mathrm{Zn}$ and ${ }^{42} \mathrm{Ca}$ were calculated according to Turnlund et al. (1982). The calculations were based on the faecal excretion of isotopes during $68-92 \mathrm{~h}$ after intake of the labelled test meal, using the following equations:

$$
\mathbf{M}^{\mathrm{AA}}=\mathbf{M}^{s}+\mathbf{M}^{n} \text {, }
$$


where $\mathrm{M}^{\mathrm{AA}}$ is the total mass of $\mathrm{Zn}$ or $\mathrm{Ca}$ recovered in the faecal sample measured by AAS, $\mathrm{M}^{s}$ is the mass of enriched ${ }^{70} \mathrm{Zn}$ or ${ }^{42} \mathrm{Ca}$ (spike) in the faecal sample and $\mathrm{M}^{n}$ is the mass of naturally occurring mineral, $\mathrm{Zn}$ or $\mathrm{Ca}$;

$$
\begin{aligned}
\mathbf{M}^{s} / \mathbf{M}^{n}=\mathrm{F}\left(\mathbf{R}_{j}^{i}\right) & =\omega^{s} / \omega^{n} \times \mathrm{A}_{j}^{n} / \mathrm{A}_{j}^{s} \times \frac{\mathrm{A}_{j}^{n} / \mathbf{A}_{j}^{n}-\mathbf{R}_{j}^{i}}{\mathbf{R}_{j}^{i}-\mathbf{A}_{i}^{s} / \mathbf{A}_{j}^{s}}, \\
\mathbf{M}^{s} & =\frac{\mathbf{M}^{\mathrm{AA}} \times \mathbf{F}\left(\mathbf{R}_{j}^{i}\right)}{1+\mathrm{F}\left(\mathbf{R}_{j}^{i}\right)},
\end{aligned}
$$

where $\mathrm{R}_{j}^{i}$ is the measured ratio of isotope $i$ to isotope $j$ in the faecal sample, $\omega^{n}$ is the atomic weight of naturally occurring mineral, $\mathrm{Zn}$ or $\mathrm{Ca}, \omega^{s}$ is the atomic weight of enriched ${ }^{70} \mathrm{Zn}$ or ${ }^{12} \mathrm{Ca}$ (spike), $\mathrm{A}_{i}^{n}$ is the atomic abundance of isotope $i$ for naturally occurring mineral, $\mathrm{A}_{i}^{s}$ is the atomic abundance of isotope $i$ for enriched ${ }^{70} \mathrm{Zn}$ or ${ }^{42} \mathrm{Ca}$ (spike), $\mathrm{A}_{j}^{n}$ is the atomic abundance of isotope $j$ for naturally occurring mineral, $\mathbf{A}_{j}^{s}$ is the atomic abundance of isotope $j$ for enriched ${ }^{70} \mathrm{Zn}$ or ${ }^{42} \mathrm{Ca}$ (spike), $i$ is the reference isotope and $j$ is the isotope enriched in ${ }^{70} \mathrm{Zn}$ or ${ }^{42} \mathrm{Ca}$ (spike).

In the present study the following equations for $F\left(R_{j}^{i}\right)$ were obtained:

$$
\begin{aligned}
& { }^{42} \mathrm{Ca} \text { faecal excretion: } F\left(R_{42}^{40}\right)=41.593 / 40.08 \times 0.647 / 79.35 \times \frac{96.941 / 0.647-R_{42}^{40}}{R_{42}^{40}-19 \cdot 60 / 79 \cdot 35}, \\
& { }^{70} \mathrm{Zn} \text { faecal excretion: } F\left(R_{70}^{68}\right)=69.447 / 65.362 \times 0.589 / 88.35 \times \frac{18 \cdot 16 / 0.589-R_{70}^{68}}{R_{70}^{68}-3.641 / 88 \cdot 35} .
\end{aligned}
$$

Fractional apparent absorption was calculated according to the following equation:

$$
\text { fractional apparent absorption }=\frac{\text { dose }-M^{s}}{\text { dose }} \times 100,
$$

where dose is the amount of enriched ${ }^{70} \mathrm{Zn}$ or ${ }^{42} \mathrm{Ca}$ administered and $\mathrm{M}^{s}$ is the amount of enriched ${ }^{70} \mathrm{Zn}$ or ${ }^{42} \mathrm{Ca}$ excreted in faeces.

Cumulative faecal excretion was determined from ${ }^{70} \mathrm{Zn}$ and ${ }^{42} \mathrm{Ca}$ in faecal samples collected after completed excretion of non-absorbed isotopes (after $>68-92 \mathrm{~h}$ after intake up until $21 \mathrm{~d}$ post-administration) according to the following equation:

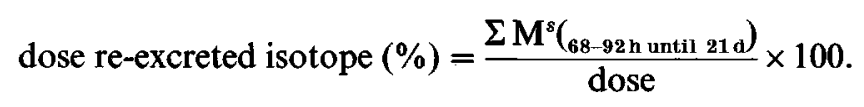

\section{Ethical considerations}

Parents were fully informed about the aims and the procedure of the study and their informed consent was obtained. The protocol was approved by the Joint Ethical Committee of the University of Aberdeen and the Grampian Health Board, Aberdeen.

\section{RESULTS}

Infant characteristics are shown in Table 1. Transit time through the gastrointestinal tract, measured as the time lapse between the administration of the faecal marker until it first appeared in the stool, ranged from 6 to $29 \mathrm{~h}$ with a mean of $18 \mathrm{~h}$.

Individual values for fractional apparent absorption of ${ }^{70} \mathrm{Zn}$ and ${ }^{42} \mathrm{Ca}$, calculated as the difference between the dose ingested and the total excretion of the isotope up to $92 \mathrm{~h}$, are given in Tables 2 and 3. Since a second faecal marker was not given after $72 \mathrm{~h}$, we included 
Table 1. Sex, age, body weight, length, gastrointestinal transit time and hours of faecal excretion included in the calculation of fractional absorption of zinc and calcium by infants

\begin{tabular}{ccccccc}
\hline \hline Infant & Sex & $\begin{array}{c}\text { Age } \\
\text { (weeks) }\end{array}$ & $\begin{array}{c}\text { Body wt } \\
(\mathbf{k g})\end{array}$ & $\begin{array}{c}\text { Length } \\
(\mathrm{m})\end{array}$ & $\begin{array}{c}\text { Transit time } \\
(\mathrm{h})\end{array}$ & $\begin{array}{c}\text { Faecal } \\
\text { excretion } \\
\text { (h) }\end{array}$ \\
\hline 1 & $\mathrm{~F}$ & 28 & 8.4 & 0.67 & 29 & 74 \\
2 & $\mathrm{M}$ & 29 & 9.6 & 0.71 & 21 & 68 \\
3 & $\mathrm{~F}$ & 30 & 8.2 & 0.68 & nd & 69 \\
4 & $\mathrm{M}$ & 18 & 6.2 & 0.64 & 6 & 81 \\
5 & $\mathrm{M}$ & 20 & 6.8 & 0.64 & 23 & 92 \\
6 & $\mathrm{M}$ & 20 & 8.2 & 0.68 & 9 & 75 \\
\hline
\end{tabular}

nd, not determined.

Table 2. Individual values for fractional absorption and cumulative re-excretion of ${ }^{70} \mathrm{Zn}$ by infants*

\begin{tabular}{ccc}
\hline \hline & \multicolumn{2}{c}{ Administered dose (\%) } \\
\cline { 2 - 3 } Infant & $\begin{array}{c}\text { Absorption of } \\
{ }^{70} \mathrm{Zn}\end{array}$ & $\begin{array}{c}\text { Cumulative re-excretion } \\
\text { of absorbed }{ }^{70} \mathrm{Zn}\end{array}$ \\
\hline 1 & $19 \cdot 2$ & 0.85 \\
2 & 25.4 & 0.88 \\
3 & 41.4 & 0.12 \\
4 & 27.6 & 0.06 \\
5 & 26.1 & 0.16 \\
6 & 63.9 & 0.59 \\
Mean & 33.9 & 0.44 \\
SD & 16.4 & 0.38 \\
\hline
\end{tabular}

* For details of procedures, see pp. 292-295.

Table 3. Individual values for fractional absorption and cumulative re-excretion of ${ }^{42} \mathrm{Ca}$ in infants*

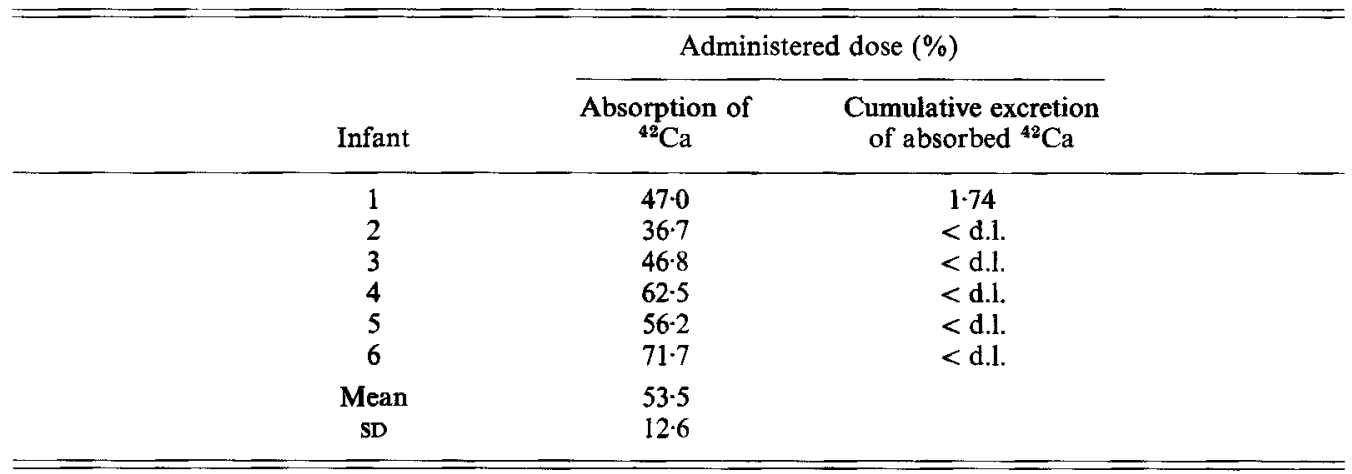

$<$ d.l., below the detection limit.

* For details of procedures, see pp. 292-295. 
the isotopes excreted in faeces during a time period of $68-92 \mathrm{~h}$ in the calculation of fractional absorption for the individual infants (Table 1). The re-excretion of absorbed ${ }^{70} \mathrm{Zn}$ and ${ }^{42} \mathrm{Ca}$ in faeces during the period $>68-92 \mathrm{~h}$ to $21 \mathrm{~d}$ after administration is also given in Tables 2 and 3. Mean fractional apparent absorption values for ${ }^{70} \mathrm{Zn}$ and ${ }^{42} \mathrm{Ca}$ were 33.9 (SD 16.4) \% (range 19.2-63.9\%) and 53.5 (SD 12.6) \% (range 36.7-71.7\%) respectively. Re-excretion of absorbed isotopes ( $>68-92 \mathrm{~h}$ to $21 \mathrm{~d}$ after administration) was found to be 0.44 (SD 0.38$) \%$ of the administered dose $\left({ }^{70} \mathrm{Zn}\right.$ ) while only one infant (baby 1) reexcreted detectable amounts of absorbed ${ }^{42} \mathrm{Ca} ; 1.74 \%$ of administered dose.

\section{DISCUSSION}

During the weaning period the infant is very vulnerable nutritionally (Herveda \& Newman, 1992). The increased amounts of semi-solid and solid foods that are being introduced, at the expense of human milk or infant formula, must provide energy and nutrients for the rapid phase of growth and development. Traditionally, weaning cereals are one of the first semi-solid foods to be given to the infant at about 4-6 months of age (American Academy of Pediatrics Committee on Nutrition, 1980; Clark \& Laing, 1990) and the nutritional composition and bioavailability of nutrients in this type of product are therefore of great importance.

Relatively high fractional apparent absorption values for both $\mathrm{Zn}$ and $\mathrm{Ca}$ from the weaning cereal labelled with stable isotopes were found in the present study. The infant cereal was based on white wheat flour with a low extraction rate and skimmed milk powder and can thus be expected to contain only low amounts of phytic acid, a potent inhibitor of mineral absorption. These results demonstrate that weaning cereals containing low amounts of inhibitors can play an important role in providing $\mathrm{Zn}$ and $\mathrm{Ca}$ to the rapidly growing infant. Very little information on $\mathrm{Zn}$ and $\mathrm{Ca}$ absorption in term infants is available for comparison with our results. Fractional $\mathrm{Zn}$ absorption from cows'-milk-based infant formulas, studied in infants by the stable-isotope technique, has been reported to be dependent on the $\mathrm{Zn}$ level in the diet, higher fractional absorption taking place at lower intakes (Ziegler et al. 1989). In the study by Ziegler et al. (1989) the mean true $\mathrm{Zn}$ absorption was found to be 16.8 (SD 5.8 ) \% at the normal level of $\mathrm{Zn}$ in infant formulas (6.58 $\mathrm{mg} \mathrm{Zn/1)} \mathrm{and} 41.1$ (SD 7.8)\% from formula containing $1.47 \mathrm{mg} \mathrm{Zn} / 1$. The labelled formula (1 1 ) was administered over approximately $24 \mathrm{~h}$. The present results thus seem to indicate that the apparent absorption of $\mathrm{Zn}$ from infant cereal containing about $1 \mathrm{mg} \mathrm{Zn}$ in a single meal (when measured under these conditions) is relatively high. More information on mineral bioavailability from weaning foods is clearly needed together with identification of dietary inhibitors and enhancers. For example, the effect of increased phytic acid levels in weaning products with a higher fibre content on mineral bioavailability in infants has not been reported. This lack of information is primarily related to the methodological difficulties involved in this type of study.

The results from the present study demonstrate that $72 \mathrm{~h}$ faecal collections are adequate for complete collections of non-absorbed stable isotopes when measuring $\mathrm{Zn}$ and $\mathrm{Ca}$ apparent absorption in infants during the weaning period. However, since some of the initially absorbed isotope will be re-excreted via the gastrointestinal tract (and in urine) during the $72 \mathrm{~h}$ following administration, true absorption will be underestimated. It is thus important to estimate the magnitude of the re-excretion of absorbed isotope in order not to introduce any significant error in the experimental data. The extent of re-excreted absorbed mineral lost via the gastrointestinal tract can be monitored by the appearance of isotopes in faeces following injection (Janghorbani et al. 1985). This technique is based on the assumption that an injected isotope is excreted in an identical manner to the native element. However, the need for venepuncture limits the use of this method when studies are 
being done in healthy, non-hospitalized infants and an alternative approach is needed. Studies of the cumulative faecal excretion of isotopes given orally can be used for this purpose. The positive slope of the excretion curve after the elimination of unabsorbed mineral is used for estimating the magnitude of re-excretion of absorbed isotope by this technique. This method has been used in a study of premature infants, demonstrating that re-entry of absorbed isotope into the gastrointestinal tract was insignificantly small for ${ }^{70} \mathrm{Zn}$. However, re-entry of ${ }^{46} \mathrm{Ca}$ was shown to be higher, about $0.5 \%$ per $24 \mathrm{~h}$ period in two premature infants (Janghorbani et al. 1985). Re-excretion of absorbed mineral is not quantitatively the same as endogenous excretion as the latter requires isotopic equilibration in the body pool which is the major reason for the observed negligible re-excretion of ${ }^{70} \mathrm{Zn}$ in contrast to the significant endogenous secretion of this element (Janghorbani et al. 1985).

Prolonged collections of faecal material in the present study showed only minor amounts of isotopes being excreted after completing the excretion of non-absorbed isotope ( $>68-92 \mathrm{~h}$ after administration). In our study we could quantify only small amounts of ${ }^{70} \mathrm{Zn}$ being re-excreted in faeces and found values below the detection limit for ${ }^{42} \mathrm{Ca}$, except for one infant (baby no. 1). Our results thus support the earlier conclusion that the simple faecal pooling method should provide a sufficiently accurate estimate of apparent absorption of $\mathrm{Zn}$ and $\mathrm{Ca}$. The more elaborate method involving analysis of individual stools and extrapolations to zero transit time in order to estimate the magnitude of reexcretion is therefore not needed (Janghorbani et al. 1985).

In the present study it was not possible to ensure a separate collection of urine and faeces since no special collection devices were used. The inclusion of urine in some of the faecal samples cannot be ruled out, resulting in an underestimate of the apparent absorption of $\mathrm{Zn}$ and $\mathrm{Ca}$. The magnitude of the underestimation is difficult to ascertain since very little information is available about the excretion of newly absorbed $\mathrm{Zn}$ and $\mathrm{Ca}$ in urine. We have recently measured the excretion of newly absorbed ${ }^{70} \mathrm{Zn}$ and ${ }^{44} \mathrm{Ca}$ after administration of bread fortified with $\mathrm{FeSO}_{4}$ or NaFeEDTA in ten adult women (Davidsson et al. 1994). Very small amounts of the administered dose of ${ }^{70} \mathrm{Zn}$ were found in complete $6 \mathrm{~d}$ collections of urine during the consumption of $\mathrm{FeSO}_{4}$ and $\mathrm{NaFeEDTA}$-fortified diets; 0.29 (SD 0.21) \% and 0.91 (SD 0.34) \% while the excretion of absorbed ${ }^{44} \mathrm{Ca}$ was $8.8(\mathrm{SD} 1.9) \%$ and $9 \cdot 8$ (SD $2 \cdot 2$ ) \% during the two dietary regimens respectively.

The total contents of $\mathrm{Zn}$ and $\mathrm{Ca}$ in the test meal were increased by 82 and $3 \%$ respectively in the test meal after addition of the stable-isotope solutions. The increase in $\mathrm{Ca}$ content can thus be regarded as negligible while the extrinsic labelling with ${ }^{70} \mathrm{Zn}$ increased the $\mathrm{Zn}$ content significantly. The increased amount of total mineral in the test meals is a frequently discussed problem related to the stable-isotope technique since stable isotopes cannot be regarded as 'true' tracers. This problem cannot be completely overcome, due to the nature of stable isotopes, but can be minimized by careful study design and high precision measurements of stable-isotope ratios. In the present study we chose to administer a relatively high dose of ${ }^{70} \mathrm{Zn}$ since one of our aims, related to the methodological part of this study, was to be able to measure accurately the faecal excretion of absorbed isotope over an extended period of time in individual stool samples. The fractional apparent absorption of $\mathrm{Zn}$ from the infant cereal would thus be assumed to be underestimated since percentage $\mathrm{Zn}$ absorbed depends on the $\mathrm{Zn}$ content of the test meal (Ziegler et al. 1989).

Another methodological aspect of the stable-isotope technique which needs to be considered is the procedure used when labelling test meals. By far the most commonly used labelling technique, which was used in the present study, is to add stable isotopes as extrinsic labels. An alternative approach would be intrinsic labelling of test meals. However, due to the very elaborate study design needed when preparing intrinsically 
labelled foods this approach was not considered in this case, The extrinsic labelling technique with $\mathrm{Zn}$ and $\mathrm{Ca}$ stable isotopes has been validated in previous studies in infants and adults. Zn absorption from intrinsically and extrinsically labelled cows' milk infant formula was identical for both infants (Serfass et al. 1989) and adult women (Egan et al. 1991), as was the absorption of $\mathrm{Ca}$ and $\mathrm{Mg}$ by low-birth-weight infants fed with intrinsically and extrinsically labelled human milk (Liu et al. 1989). Similarly the absorption of intrinsically and extrinsically added Ca was not significantly different in adults given whole-wheat flour (Weaver et al. 1992) or milk (Martin et al. 1989). Thus, there is little reason to believe that intrinsic and extrinsic stable-isotope labels added to infant cereals would be utilized differently by infants.

We hope that the recent development of stable-isotope techniques for studies of mineral absorption in infants will result in increased research activity in this field of infant nutrition. The large inter-individual variation in $\mathrm{Zn}$ and $\mathrm{Ca}$ absorption observed in the present study needs be studied further to evaluate also the day-to-day and meal-to-meal variation in mineral absorption by infants. Thus, carefully designed studies are needed when evaluating the influence of different dietary factors on mineral absorption during infancy. The possibility of studying several minerals simultaneously and of repeating studies over a period of time to investigate the effect of age on mineral absorption should be considered for future studies.

\section{REFERENCES}

Abrams, S. A., Esteban, N. V., Vieira, N. E., Sidbury, J. B., Specker, B. L. \& Yergey, A. L. (1992). Developmental changes in calcium kinetics in children assessed using stable isotopes. Journal of Bone and Mineral Research 7 , $287-293$.

Abrams, S. A., Esteban, N. V., Vieira, N. E. \& Yergey, A. L. (1991). Dual tracer stable isotopic assessment of calcium absorption and endogenous fecal excretion in low birth weight infants. Pediatric Research 29, 615-618.

Abrams, S. A., Yergey, A. L., Schanler, R. J., Vieira, N. E. \& Welch, T. R. (1994). Hypercalciuria in premature infants receiving high mineral-containing diets. Journal of Pediatric Gastroenterology and Nutrition 18, $20-24$.

American Academy of Pediatrics Committee on Nutrition (1980). On the feeding of supplemental foods to infants. Pediatrics 65, 1178-1181.

Clark, B. J. \& Laing, S. C. (1990). Infant feeding: a review of weaning. Journal of Human Nutrition and Dietetics 3, 11-18.

Davidsson, L. (1994). Minerals and trace elements in infant nutrition. Acta Paediatrica Suppl 395, $38-42$.

Davidsson, L., Kastenmayer, P. \& Hurrell, R. F. (1994). Sodium iron EDTA (NaFe(III)EDTA) as a food fortificant: the effect on the absorption and retention of zinc and calcium in women. American Journal of Clinical Nutrition 60, 231-237.

Dixon, W. J. \& Massey, F. J. (1969). Introduction to Statistical Analysis, pp. 328-330. New York: McGraw Hill.

Egan, C. B., Smith, F. G., Houk, R. S. \& Serfass, R. E. (1991). Zinc absorption in women: comparison of intrinsic and extrinsic stable-isotope labels. American Journal of Clinical Nutrition 53, 547-553.

Ehrenkranz, R. A., Ackerman, B. A., Nelli, G. M. \& Janghorbani, M. (1984). Determination with stable isotopes of the dietary bioavailability of zinc in premature infants. American Journal of Clinical Nutrition 40, 72-81.

Ehrenkranz, R. A., Ackerman, B. A., Nelli, G. M. \& Janghorbani, M. (1985). Absorption of calcium in premature infants as measured with a stable isotope 46-Ca extrinsic tag. Pediatric Research 19, $178-184$.

Ehrenkranz, R. A., Gettner, P. A., Nelli, G. M., Sherwonit, E. A., Williams, J. E., Ting, B. T. G. \& Janghorbani, M. (1989). Zinc and copper nutritional studies in very low birth weight infants: comparison of stable isotopic extrinsic tag and chemical balance methods. Pediatric Research 26, 298-307.

Götz, A. \& Heumann, K. G. (1987). Heavy metal trace determination with a compact thermal ionization quadrupole mass spectrometer. Part 2. Analysis of food samples. Fresenius Zeitschrift für Analytische Chemie 326, 118-122.

Hervada, A. R. \& Newman, D. R. (1992). Weaning: historical perspectives, practical recommendations, and current controversies. Current Problems in Pediatrics 22, 223-240.

Hillman, L. S., Tack, E., Covell, D. G., Vieira, N. E. \& Yergey, A. L. (1988). Measurement of true calcium absorption in premature infants using intravenous ${ }^{46} \mathrm{Ca}$ and oral ${ }^{44} \mathrm{Ca}$. Pediatric Research $23,589-594$.

International Union of Pure and Applied Chemistry (1991). Isotopic composition of elements 1989. Pure and Applied Chemistry 63, 991-1002.

Janghorbani, M., Young, V. R. \& Ehrenkranz, R. A. (1985). Isotopic methods in the study of mineral metabolism of infants with special reference to stable isotopes. In Trace Elements in Nutrition of Children. Nestlé Nutrition Workshop Series, pp. 63-86 [R. K. Chandra, editor]. New York: Raven Press. 
Johnson, P. E. \& Canfield, W. K. (1989). Stable zinc and copper absorption in free-living infants fed breast milk or formula. Journal of Trace Elements in Experimental Medicine 2, 285-295.

Liu, Y.-M., Neal, P., Ernst, J., Weaver, C., Rickard, K., Smith, D. L. \& Lemons, J. (1989). Absorption of calcium and magnesium from fortified human milk by very low birth weight infants. Pediatric Research 25, 496-502.

Martin, B. R., Weaver, C. M. \& Smith, D. L. (1989). Calcium absorption from milk vs. calcium carbonate in college age women using stable isotopes. FASEB Journal 3, A771 Abstr.

Moore, L. J. \& Machlan, L. A. (1972). High accuracy determination of calcium in blood serum by isotope dilution. Mass Spectrometry 44, 2291-2296.

Moore, L. J., Machlan, L. A., Lim, M. O., Yergey, A. L. \& Hansen, J. W. (1985). Dynamics of calcium metabolism in infancy and childhood. I. Methodology and quantification in the infant. Pediatric Research 19, 329-334.

Serfass, R. E., Ziegler, E. E., Edwards, B. B. \& Houk, R. S. (1989). Intrinsic and extrinsic stable isotopic zinc absorption by infants from formulas. Journals of Nutrition 119, 1661-1669.

Turnlund, J. R. (1991). Bioavailability of dietary minerals to humans: the stable isotope approach. Critical Reviews of Food Science and Nutrition 30, 387-396.

Turnlund, J. R., Michel, M. C., Keyes, W. R., King, J. C. \& Margen, S. (1982). Use of enriched stable isotopes to determine zinc and iron absorption in elderly men. American Journal of Clinical Nutrition 35, 1033-1040.

Weaver, C. M., Heaney, R. P., Martin, B. R. \& Fitzsimmons, M. L. (1992). Extrinsic vs intrinsic labeling of the calcium in whole-wheat flour. American Journal of Clinical Nutrition 55, 452-454.

Yergey, A. L., Abrams, S. A., Vieira, N. E., Eastell, R., Hillman, L. S. \& Covell, D. G. (1990). Recent studies of human calcium metabolism using stable isotopic tracers. Canadian Journal of Physiology and Pharmacology 68, 973-976.

Ziegler, E. E., Serfass, R. E., Nelson, S. E., Figueroa-Colon, R., Edwards, B. B., Houk, R. S. \& Thompson, J. J. (1989). Effect of low zinc intake on absorption and excretion of zinc by infants studied with $70-\mathrm{Zn}$ as an extrinsic tag. Journal of Nutrition 119, 1647-1653. 